\title{
Cultural Identity in Everyday Interactions at Work: Highly Skilled Female Russian Professionals in Finland
}

I Malgorzata Lahti'

PhD Student, Department of Communication, University of Jyväskylä, Finland

\begin{abstract}
The dominant research strands into social interaction in culturally diverse workplaces have focused on issues of organizational efficiency and discrimination, and they have treated cultural identity as static, monolithic, and universally shared. This study aims to problematize this view. It is argued that our understanding of cultural workplace diversity could be extended through the integration of interpretive and critical interpersonal communication theorizing on cultural identity as dynamic and processual, constructed between and among people in everyday workplace interactions and in relation to larger social, political, and historical forces. This argument is illustrated by an analysis of in-depth interviews with 10 female Russian immigrants in Finland who performed interactionintense knowledge work. The women talked about their everyday workplace interactions and how they thought Russian identity mattered in them. These data were analyzed with the inductive method of interpretive description designed to provide a systematic description of the phenomenon delineating its characteristic themes and accounting for individual variations within it. The analysis led to the identification of four communication sites for distinct formations of Russian identity: expressing professionalism, managing initial encounters, facing stigma, and facilitating intercultural learning. The findings offer novel insights into social interaction in culturally diverse workplaces with implications for both employee well-being and organizational processes.
\end{abstract}

\section{KEY WORDS}

Cultural identity / cultural workplace diversity / highly skilled immigrants / interpersonal communication / workplace interactions

\section{Introduction}

ost examinations of social interaction in culturally diverse workplaces have been conducted from mainstream and critical management/organizational perspectives, and they have examined phenomena related to either organizational efficiency or discrimination (e.g., Richardson and Taylor 2009, van der Zee et al. 2009). To that purpose, both strands have employed conceptualizations of cultural identity as static, monolithic, and universally shared. The aim of this article is to problematize this view and argue that our understanding of cultural workplace diversity could be extended through the integration of interpretive and critical interpersonal communication theorizing on cultural identity. More specifically, this study looks into how culturally nonmainstream employees experience the formation of their cultural identities in their everyday workplace interactions.

\footnotetext{
${ }^{1}$ E-mail: malgorzata.lahti@jyu.fi
} 
Workplace diversity scholarship has been strongly influenced by the polemics surrounding the neoliberal diversity management ideology and the antidiscrimination movement in the United States (e.g., Holvino and Kamp 2009, Mannix and Neale 2005). Owing to their distinctive philosophical and political origins, studies of social interaction in culturally diverse workplaces can be broadly divided into those that relate the effective management of staff in culturally diverse teams and corporations to organizational efficiency, and those that investigate discrimination experienced by ethnic minority employees in mainstream culture organizations (Lahti and Valo 2012).

These examinations have taken discrete approaches to treating cultural identities (see also Lauring 2009). The organizational efficiency perspective sees cultural identities as sets of values, schemes for perception and conduct, and the accompanying psychological states that are situated inside individuals and revealed in interaction. Issues of organizational efficiency have been investigated from the theoretical perspectives of information and decision making, and social identity and categorization (e.g., van Knippenberg et al. 2013). The information and decision making approach examines how cultural differences associated with employees' culturally shaped values, knowledge, skills and perspectives hinder or enhance organizational performance in terms of, for example, information processing, problem solving, or innovation (e.g., Peltokorpi 2007, Stevens et al. 2008). The social identity and categorization perspective considers diversity of cultural memberships as triggering the formation of cultural subgroupings that interferes with organizational functioning as it encourages out-group bias and tensions, weakened team and organizational identification, or impeded information sharing (e.g., Ferguson and Porter 2013, van der Zee et al. 2009).

The discrimination tradition, in turn, approaches cultural identity as a subjugating categorization imposed onto individuals by outside macro-level structures or ideologies. The framework has relied on critical theories of power and intergroup relations to uncover how organizational power inequalities subject representatives of minority identity groups through sanctioning mistreatment and exerting pressures to conform to the mainstream organizational culture (e.g., Hopson and Orbe 2007, Richardson and Taylor 2009).

In both research strands, cultural identities are assumed to remain the same throughout different contexts and interactions (as static), comprise a finite set of meanings and experiences (as monolithic), and be the same for all the members of the group (as universally shared). Recently criticism has been voiced as to the need for approaches that would acknowledge the nuanced, dynamic, processual, and emergent character of cultural workplace diversity (e.g., Lauring 2009, Piller 2011). As a few researchers have now demonstrated (e.g., Lauring 2011, Ryoo 2005, Tanaka 2006), organizational experiences of ethnic minority employees extend beyond oppression; similarly, intercultural interactions in international corporate contexts do not occur in a social, political, and historical void. In addition, the few existing studies exploring cultural diversity as a subjective and intersubjective construct cocreated and negotiated in organizational members' interactions with one another (e.g., Barinaga 2007, Ely and Thomas 2001) have demonstrated that cultural diversity may be given multiple, creative, and even contradictory interpretations that inform organizational members' practices in significant ways.

In this article, it is argued that examining identity processes as a means in itself could offer valuable knowledge about cultural workplace diversity. An interpretive interpersonal communication perspective could yield insights into how individuals come 
to understand their cultural identities in their everyday interpersonal interactions at work. To strengthen the validity of knowledge claims, such an investigation should further be informed by a critical perspective sensitive to the role of power and privilege in the construction of cultural identities in interaction (Collier 1998). The present study applies integrated interpretive and critical interpersonal communication theorizing to examine how highly skilled female Russian professionals in Finland experience their cultural identities as they are formed across workplace conversations and relationships.

\section{Cultural identity processes in everyday interactions at work}

Cultural identity is defined here as a contextually situated unfolding process of coming to know who one is in terms of group-based histories, symbols, meanings, and practices in relation to one's peer coworkers, subordinates, supervisors, customers, and business partners. Cultural identities are historical, relational, and contextual constructs that have both permanent and fluid components (Collier and Thomas 1988). Their enduring characteristics entail shared symbols, names, labels, and norms that are passed on to new group members and drawn upon to distinguish between insiders and outsiders (Collier 1998). Identities also have dynamic aspects. Rather than situated inside individuals and revealed in interaction, cultural identities are formed (experienced, enacted, and negotiated) between and among persons in specific interpersonal communication situations: in conversations, relationships, and interactions with members of other groups, and in the context of social and historical developments (Collier 1998). Moreover, cultural identities are multifaceted and heterogeneous as individuals are members in a variety of cultural groups such as ethnic, linguistic, religious, national, or political (Collier 1998).

Vital aspects of the process of identity formation include avowal and ascription that refer to, respectively, enacted presentation of self and identities one is attributed by others (Collier and Thomas 1988). Hecht et al. (1993) further elaborated on cultural identity processes in communication theory of identity that conceptualizes identity as consisting of four layers or frames: the personal, enacted, relational, and communal frames. The personal frame refers to one's self-concept and sense of well-being; the enacted frame examines how identities are expressed in conversations; the relational frame pertains to how one's identities are formed in one's relationships with others; the communal frame focuses on the identity shared by a group of people (Hecht et al. 1993). To illustrate how these frames operate, an individual could consider her specific membership in a cultural group as an important source of meanings, perceptions, and motivations in her daily working life (personal frame); she could express her cultural identity by enacting specific cultural practices or through talk about her background in everyday conversations with her colleagues (enacted frame); she could be perceived as culturally different by her coworkers who would have specific expectations of her related to her cultural background (relational frame); and she could be affected by the images of her cultural group circulating in the mainstream society, for example, in the media (communal frame).

Identity formation is a communicative process that involves negotiations between and among the individual, the enactment, the relationship, and the community (Hecht and Faulkner 2000, Golden et al. 2002). The negotiations are geared toward achieving a match between identity frames; however, the frames are not always reconcilable and there may be discrepancies or identity gaps between them (Jung and Hecht 2004). 
For instance, persons may experience, and therefore need to manage, tensions between their self-concept and the identity ascribed to them by others. An individual may not experience herself as culturally different at work, yet be perceived as "other" by her colleagues. There may also be an identity gap between an individual's self-view and what she expresses in interactions. A person who is a member of a group stigmatized in the given society may value her background and experience it as central to her sense of self, yet choose to closet it when meeting new business partners for fear of facing hurtful or threatening reactions and ascriptions. Despite such inconsistencies and tensions, the frames nevertheless coexist shaping an individual's identity (Jung and Hecht 2004).

It is important to emphasize that our sense of self comprises multiple personal and group-based identities stemming from our unique qualities and experiences, as well as our numerous group memberships and roles (Collier and Thomas 1988, Spreckles and Kotthoff 2009). Cultural identity is therefore not only multifaceted and multilayered, but also only one among many other identities through which persons may define and orient themselves toward others in different communication situations. Hence, identities are best described as emergent and potential. Among the properties of cultural identities, Collier and Thomas (1988) list salience (how visible they are in a specific situational context), scope (how widely held and generalizable they are in that context), and intensity (how strongly the participants in interaction feel about them). The salience, scope, and intensity of particular cultural identities will vary depending on the situation, context, topic, and relationship. In any communication situation, the participants will draw on aspects of their identities that they perceive to be of relevance for the given encounter, and they will further negotiate their salience, scope, and intensity with the other interactants. Not only will some identities emerge as more prominent than others, but the degree to which the interactants perceive them as important or generalizable may change throughout the conversation. Cultural identity may not always be a relevant frame for individuals to make sense of who they are in social interaction, the workplace context included. In fact, the workplace context should be considered as potentially highly consequential for people's cultural identity processes as it limits and enables specific experiences of self, roles, relationships, exchanges, activities, shared symbols, values, and goals. Spreckles and Kotthoff (2009, p. 415) illustrate this point with the example of an Italian and Swedish surgeon performing an operation together at a Zurich hospital. In this particular situation, their professional identities, including expertise in particular surgical procedures, as well as their communication competence in the professional jargon of the shared language will most likely emerge as relevant. Their ethnic, national, or even linguistic identities will not necessarily be of importance.

At the same time, it would be naïve to consider persons in interaction as equal agents who unproblematically express and get others to agree upon their desired identities as perceived appropriate for the given context; the negotiation of cultural identities is inherently infused with hierarchy and power inequalities (Collier 2005, Piller 2011). The concept of agency is useful here to describe the individual's "ability to choose and enact a range of actions" (Collier 2005, p. 244). One's agency in identity negotiations in interactions with others at work may be enabled and constrained by factors such as access to cultural and linguistic resources, roles and positions in the organization, or sociostructural factors (see also Piller 2011). In other words, a person's ability to claim her desired identities will be affected by issues such as her proficiency in the organizational language, her position in the interaction as a subordinate or supervisor, or the prestige of 
her cultural group. Collier $(1998,2005)$ reminds us that the process of forming cultural identities in interaction may be infused with power, privilege, history, and ideology, an issue that ties in with the concept of communal identity frame discussed earlier. Employees from marginalized or stigmatized groups may, in some situations, have little agency in negotiating subjugating cultural categorizations ascribed to them by others in interactions as they face prejudice or discrimination. By the same token, an avowal of a specific cultural identity may be a risky and politically signified act.

This study focuses on the experiences of highly skilled female Russian professionals in Finland. Underlying this choice of participants is a conjecture that their experiences of cultural identity formation processes in workplace interactions may be particularly rich and nuanced as they are knowledge workers who simultaneously hold possibly problematic cultural group memberships.

\section{Highly skilled female Russian professionals in Finland}

Russians are the second largest immigrant group in Finland after Estonians. In 2012, there were 30,183 Russian citizens living in Finland, and slightly over 57\% of them were women (Official Statistics of Finland 2013). This number does not represent all the persons with a Russian background as some of them are Finnish citizens.

Studies of Finns' attitudes toward immigrants indicate that, despite their ethnic proximity to Finns, Russians continue to be one of the least liked immigrant groups alongside the visibly different immigrants from Somalia and Arab countries (Jaakkola 2005, 2009). These negative attitudes have been attributed to the history of difficult political and social relations between Finland and Russia, as well as Russia's lower status as a poor postcommunist economy (e.g., Forsander 2001, Jaakkola 2005).

Researchers have further suggested that being a Russian woman in Finland may entail a unique set of experiences. Jasinskaja-Lahti et al. (2002), for instance, found that while male immigrants across different ethnic groups in Finland generally seemed to be more likely victims of prejudice and discrimination, Russian women reported facing discriminatory acts more than any other group. This may seem surprising since female Russian immigrants bear a significant resemblance to women in the Nordic states: they also are "white," well educated, and used to combining work with family life (Saarinen 2007). However, Russian women in the "female-friendly" Nordic states may face degrading social categorizing brought on by the deterioration of women's social and economic position following the collapse of the socialist rule (Saarinen 2007). In the Finnish social reality, the implication of this has been that female Russian immigrants may be confronted with prostitution-related ascriptions and harassment, and having to develop coping strategies such as closeting one's background (Kyntäjä 2005, Saarinen 2007, Säävälä 2010).

At the same time, the Finnish working life has been undergoing deep transformations. The trend toward knowledge work has been increasingly pronounced, adding an extra emphasis on educational background, professional expertise, and skills (e.g., Kasvio et al. 2010, Pyöriä 2006). Also the neoliberal ideology of diversity management that promotes individualism and meritocracy based on individuals' unique combinations of competencies, therefore rendering cultural diversity among employees as of value for the organization (e.g., Holvino and Kamp 2009), has made inroads into the Finnish 
workplace and into the social discourse on multiculturalism in Finland. Bodies such as the Ministry of Labor have continuously emphasized that Finland needs foreign highly educated innovative professionals (Jaakkola 2009). It is noteworthy that Russians are one of the best educated immigrant groups in Finland (Sutela 2005). When examined against the spectrum of different ethnic minority groups, Russians have fared quite well on the Finnish labor market, making it to the second best group according to employment level with a 40-50\% employment rate (Joronen 2005).

Highly skilled female Russian professionals are not exceptional in Finnish workplaces. Little is known, however, about their lived experiences in organizational contexts. It appears that being a female Russian professional may entail nuances and paradoxes as one navigates among a number of contradictory themes, perspectives, and expectations where the privilege of being a "white," independent, and highly educated expert is intertwined with stigmatization operating at the intersection of gender and ethnicity. Valuable insights into cultural workplace diversity could be gained by exploring how these women experience their cultural identity as formed in their workplace conversations and in relationships with their coworkers, customers, and business partners. The traditional perspectives taken in cultural workplace diversity research would fail to recognize the complexity inherent in cultural identity processes. Instead, treating cultural identities as fluid and emergent, residing between and among people and in relation to the larger context offers a way of teasing out patterns of meaning that can, in turn, expand our understanding of social interaction in culturally diverse workplaces, especially concerning employee well-being and organizational processes. This study extends cultural workplace diversity research by taking an integrated interpretive and critical interpersonal communication perspective on cultural identity to answer the following questions:

RQ1: How does Russian identity matter to highly skilled female Russian professionals as they make meanings about their workplace interactions?

RQ2: How do they perceive the unfolding of Russian identity formation processes in specific contexts at work?

RQ3: What general patterns in their experiences can be identified?

\section{Methodology}

\section{Method}

The purpose of this study is to develop knowledge about cultural identity processes in everyday workplace interactions that is founded in the perspectives and worldviews of the people involved, and that would be applicable to informing practical understanding. To fit this research imperative, the method of interpretive description was adopted.

Interpretive description was developed in qualitative health research out of concern that the established qualitative methods such as ethnography, phenomenology, or grounded theory produced insights incompatible with the field's context-bound and practice-oriented questions (Thorne 2008). Interpretive description is an inductive analytic approach designed to capture themes and patterns within the subjective perceptions to generate an understanding of the phenomenon that yields pragmatic implications (Thorne et al. 2004). The method embraces an interpretive ontology that acknowledges 
the subjective view of reality and the constructed and contextual nature of human experience (Thorne 2008). Studies employing the method draw on small data samples gathered through such data collection strategies as interviews, participant observation, or document analysis to build a coherent account of the experiential knowledge of the phenomenon (Thorne et al. 2004). The product of an interpretive description is a systematic conceptual description of the phenomenon that both delineates its characteristic themes and patterns, and considers the inevitable individual variations within it (Thorne et al. 2004).

\section{Respondents and data collection}

The study is based on thematic interviews with first-generation female immigrants who identified themselves as Russian and performed interaction-intense knowledge jobs. The sampling was guided by the desire to obtain a broad variety of views on the experience of being a highly skilled female Russian professional in Finland. The respondents were searched through organizations that brought together Russian immigrants and the researcher's own contacts. Two respondents were referred to the researcher by one of the participants. Information about the research project, such as phenomena under investigation, confidentiality issues, and the researcher's own background as a female Polish immigrant in Finland, was given to the respondents in advance.

Ten female Russian immigrants participated in this study. The respondents' age ranged from the mid-20s to mid-50s, and their time of stay in Finland from 2 to 22 years. The women lived in different regions of the country: Eastern Finland, Central Finland, and the south of Finland, including Helsinki. Their occupations were financial manager, researcher and lecturer, travel agent, practical nurse, international affairs coordinator, coordinator and information officer, sales and marketing manager, IT specialist, and arts teacher.

The interviews were conducted between May 2011 and December 2012. Three interviews were done face-to-face and the others through Skype video-calling. All the interviews were digitally recorded. The choice of the interview language (Finnish or English) was left to the respondents; 8 interviews were done in Finnish and 2 in English. Out of 10 participants, 9 had a good knowledge of Finnish (with some of them being fluent in Finnish) that enabled them to express themselves with ease. The fact that the researcher is not a native speaker of Finnish helped eliminate issues related to self-presentation in a second language. The interviews lasted between 1 and 1.5 hours, yielding around 14 hours of recording.

The project did not aim at cataloguing Russianness. Defining Russian cultural identity was left to the respondents themselves. The researcher used an interview guide that consisted of the following themes: one's sense of self as a Russian at work, the salience and meaning of being Russian in specific workplace communication situations, interpersonal relationships, and in the working community. Data acquisition was guided by the idea that the way people make sense of the social world is grounded in their everyday experiences (Mason 2002). The goal of the interviews was to construct meaningful knowledge about how cultural identity related to specific situations, practices, experiences, and perceptions. The respondents were asked specific questions about working life situations and events in which cultural identity was possibly visible. The interviews 
were in the shape of "conversation with a purpose" (Burgess 1984) whereby the respondent and the interviewer actively engaged in discussing relevant events, issues, and opinions. The interview was approached as a site of knowledge construction since the knowledge produced resulted from the joint efforts of the interviewer and the respondent in recalling relevant experiences "from which they think, talk, act and interpret" (Mason 2002, p. 227).

\section{Data analysis}

The respondents described a range of workplace communication situations that included interactions with peer coworkers, supervisors, subordinates, clients, and business partners and in work-related service encounters where they were customers. Across these accounts, there was variability in meanings given to Russian identity and in the degree to which it was perceived as salient, intense, and generalizable in interactions.

The method of interpretive description required a strategy for data analysis that would enable a delineation of main patterns in the data but allow for the variability within these patterns to show. For that purpose, qualitative content analysis, which is an iterative and reflexive process of identifying, coding, and categorizing patterns in the data, was adopted (e.g., Mayan 2009). To elaborate on the relationship between interpretive description and qualitative content analysis in this study, the former one is a method that entails a set of ontological and epistemological assumptions, as well as prescriptions about the final product of the analysis. The latter is treated as a set of guidelines and procedures for organizing, grouping, and transforming the data.

The interviews were transcribed and parts of the transcripts where the respondents talked about cultural identity issues in workplace interactions were identified. The initial coding of these items was influenced by the theoretical framework of the study regarding aspects of identity processes such as identity frames and interaction between them, identity salience, intensity, and scope. As the analysis progressed, it transpired that this initially evident conceptual organization did not match the richness of the data. A framing emphasizing specific meanings accorded to manifestations of Russian identity was recognized as a better alternative. The items were grouped and sorted into patterns, and relationships between the items were searched to build categories, such as "Cultural expertise," "Salient identity markers," or "Russian customs and traditions." Items within each category were read through again and subcategories within the categories were developed recognizing the situation, topic of interaction, context, and relationship ("Cultural expertise: Being asked to interpret for Russian customers," "Salient identity markers: Customers asking about one's background," or "Russian customs and traditions: Bringing Russian dishes for colleagues to try"). Attention was paid to exceptional instances and contrary cases; in the course of the analytic process, conceptual linkages were expanded to include instances of cultural identity not being formed as an important aspect of the researched phenomenon. Rather than happening in a sequence, the process was circular and entailed simultaneous collection and analysis of data that mutually informed each other (Sandelowski 2000).

Methodological prescriptions as to the final product of an interpretive description influenced many of the choices in the construction of findings and were especially influential in the stage of weaving the categories into final themes and making the 
final inferences. The goal of interpretive description does not involve generating a completely new truth about the phenomenon (Thorne et al. 2004). Rather, the data are structured and sequenced to produce a "tentative truth claim" about what is common or shared within people's experiences of the phenomenon (Thorne et al. 2004, p. 4). The particular choice of thematic concepts serves to reveal patterns within the data that would have been obscured through some other presentation framework (Thorne 2008). A number of options for plotting the categories into themes were considered along the dimensions of types of interactions (from interactions in established work communities to interactions with customers and business partners), topic (from work-related to informal interactions), and scope and intensity (from deterministic to fluid understandings of cultural identity). The final conceptualization structuring the data illuminates specific types and aspects of workplace interactions as contexts for distinct formations of Russian identity. This structuring and sequencing was decided on as the most effective and applicable device for rendering new knowledge about the phenomenon.

\section{Possible sites for Russian identity formation}

The following four themes denote specific types and aspects of workplace interactions as critical communication locations or sites where Russian identity may be formed with distinct meanings: expressing professionalism, managing initial encounters, facing stigma, and facilitating intercultural learning.

\section{Expressing professionalism}

Russian identity was associated with expressions of professionalism in the context of interacting with and relating to others in work-related situations. Russianness was conceptualized as a set of values and qualities that shaped one's work ethics and therefore one's behavior at work, as well as possession of culture-specific knowledge and skills that were organizationally valuable resources.

Russian identity appeared as central to how some respondents defined their sense of self and enactments as professionals. In these experiences Russianness emerged as highly salient, important, and widely generalizable as it was either invoked or rejected to claim a positive professional identity. Russianness was associated by some respondents with supreme values and qualities that shaped one's work ethics, such as ambition, perfectionism, efficiency, solidarity, wholehearted commitment, and even obsession with work. It was eagerly avowed and presented as a vital source of motivations and enactments, a permanent aspect of how one communicated at work, and a prominent aspect of one's relationships with coworkers and clients. Not surprisingly, this experience of cultural identity was further related to making polarized comparisons between own Russian professional excellence and the unprofessionalism of Finns as exemplified in the attitudes and actions of one's colleagues. To illustrate, one of the respondents who worked as a practical nurse at an old people's home noted that she was popular with her patients because of her Russianness. She described herself as a reliable, trustworthy, and attentive caregiver, and attributed these qualities 
to her Russian background. She further contrasted her working style with that of her forgetful and inconsiderate Finnish workmates:

I've never heard anyone say: "I don't want you to take care of me because you're a foreigner." A lot of our patients like me precisely because I'm Russian. There are a few grannies who know that I'm Russian and they always say: "It's so good that you're here." They remember that if I've made a promise, I'll keep my word. Other nurses most likely forget. Each of our patients has an alarm and sometimes they'll ring it ten or even twenty times to get attention, but when I'm working the shift, they know it's enough to ring once and I'll be there.

Drawing on the concept of superior Russian work ethics could be related to the experience of being a member of a negatively stereotyped group and the resulting urge to improve the group's image (Collier 1998). It appears, however, that some participants who shared the highly positive perception of "Russians as superior workers" did not make a point of enacting these culturally signified qualities and experienced their professional identity as firmly situated in the Finnish working life context. One needed to adopt "Finnish values" and "Finnish communication style" to succeed at work, while Russianness could be engaged in one's private life.

Russian identity was also given a negative interpretation as a flawed mentality universally shared by all Russians that was characterized by a lack of commitment, laziness, dishonesty, greed, and a stifling preoccupation with power and status. This undesirable cultural membership was subsequently renounced to build an argument about one being an exceptional Russian, a competent employee despite one's Russian background. Constructing a positive professional identity through rejection of Russianness could stem from the internalization of negative stereotypes about one's group and the subsequent need to quit the problematic membership (see also Barinaga 2007).

A contrasting view also emerged that deemed the notion of "national character" as redundant in describing one's experiences as a professional. The demands, characteristics, and content of expert knowledge work were seen as shaped by culture-neutral universal or global norms and guidelines that erased issues of cultural memberships and gave prominence to individualized self-made postmodern identities. Other learnable qualities and skills, such as universal professional competencies or communication competence in the organizational language, were perceived as more significant and prominent in one's self-experience, enactments, and relationships in task-related interactions. Fluency in Finnish emerged as a denominator of social power in workplace interactions that dissolved the concern of, what some felt to be excessively discussed, prejudice and discrimination toward certain cultural groups in Finland. As one respondent commented, no matter how "prestigious" one's nationality, one could easily be left out of important workplace conversations if one had not made the effort to learn the language. "As long as you know Finnish, it really doesn't matter where you're from," she stated.

Apart from denoting values and qualities imbuing members of a cultural group with specific characteristics, Russianness also emerged in relation to professionalism as possession of culture-specific knowledge and skills. The recent years have seen an intensification of business relations between Russia and Finland, and an inflow of affluent Russian tourists and investors. Priority given to providing quality service to Russian customers and partners was evident in the data as the respondents' Russian identities were 
used by their employers to that end. Those women who were employed in organizations that had Russian customers or business partners were reminded of their background when their knowledge of the Russian market, business culture, or language was invoked by others. Even though their job description did not specifically include interpreting and translation, many were sporadically asked for help by their colleagues or supervisors in handling Russian documents; assisting Russian customers, guests, and business partners; handing out advice on Russian business etiquette. Even if being Russian was not otherwise central to their sense of self, the respondents did not mind or even expected to have their valuable cultural expertise invoked by others. Many expressed views that if not utilized, these resources would go to waste. Some persons performing jobs where they could not apply their Russian language skills and cultural knowledge talked about considering changing employment for one where the asset of being Russian would be more prominent. This experience of Russianness bore traces of the individualized and meritocratic discourse of diversity management. It appeared to be less problematic than the construction of the "superior Russian employee" as it comprised very specific, demonstrable, and applicable knowledge and skills that had an obvious market value and could be exercised at one's own will without aligning oneself with a specific cultural group membership.

This construction of Russianness was further related to intraethnic bias and conflict. The data contain accounts of how being Russian could acquire a discrete flavor of acrimoniousness, antagonism, and competitiveness in relation to another Russian or ethnically close colleague. To illustrate, one of the respondents told the story of a difficult relationship she had had with a fellow Ukrainian coworker that resulted in that person getting fired:
In [that workplace] there was a Ukrainian lady that was giving me a lot of trouble. She was the only Russian-speaking [staff member] and then I appeared. My boss gave me a lot of duties to try, and everything she gave me she was satisfied with. So half of [the Ukrainian woman's] duties became mine, which she didn't like. She realized that she could lose her place-she never would because we were doing different things. But she started to openly say different things, not to speak to me. So we had conversations with her [...] and then she started to behave just uncontrollably and she was fired. I've never had problems with Finns but always with Russians. It's a really strange thing, I think it's competition.

The respondent associated her colleague's openly aggressive behavior toward her with feelings of threat as she also was fluent in Russian and began to take over the woman's unique responsibilities. Such experiences of intraethnic bias and conflict are not easily explained with the traditional theoretical perspective of social identification and categorization. According to this approach, members of a disadvantaged group will help one another to improve the group's status; however, insights could be drawn from the alternative framework of positioning theory (Taylor et al. 2008). The theory encourages us to consider how individuals may use their minority status in the workplace as a source of personal gain. By claiming specific cultural expertise, one may enjoy the position of a cultural expert that further makes one unique and indispensable in the organization. The arrival of another group member possessing similar resources, much as it may improve the status of the group as such, weakens the critical value of one's cultural resources and undermines one's expert position. 


\section{Managing initial encounters}

Russianness also denoted unusual biographic information. Interactions with strangers at work were a communication context critical for the surfacing of Russian identity since they entailed negotiations about the meaning and significance of one's visibly different background.

A strong majority of the respondents felt that Russian identity was easily ascribable and therefore not closetable due to salient identity markers such as speaking with a Russian accent or having a Russian-sounding name. These involuntary cues made information about one's Russian background easily available to others. While the women had already negotiated their preferred identities in their established relationships in the working communities, initial interactions with newly met customers, colleagues, or business partners were critical situations where the meaning and significance of one's cultural background would possibly need to be negotiated anew. Indeed, the intricacies of explaining one's background to strangers were described with great detail: people asking with different degrees of directness, sometimes only after a longer involvement, and sometimes not at all. Being asked stirred contradictory emotions that were related to how salient and intense the respondents wanted their cultural identities to be in the given situation. Some welcomed the interest, some did not care whether and when they would be asked; others considered their cultural identity to be private and being ascribed Russianness through requests to discuss it with complete strangers in a workrelated situation was, to them, an imposition. This was especially the case in one-off customer service interactions. In this sense, revealing information about one's cultural background was associated with relational development. It was the sort of information one would reveal only after a longer involvement or when more interactions with the specific person were expected.

It also appeared that the respondents were, to some degree, in control of the disclosure, choosing whether and when to reveal or confirm their cultural background. Ideas about disclosing one's identity differed depending on how central Russianness was to one's sense of self at work. Those who saw their professional behavior as infused with Russianness made a point of telling others about their background straight away. One of the participants, for instance, described: "I'm proud that I'm Russian, that I have a strong educational background and expertise. So yeah, I tell everyone that I'm Russian straight away, definitely." It was acknowledged that some Russians may want to closet their identity for fear of negative repercussions. A few respondents reported closeting their background when their customers made provocative insulting comments about Russians. The decision concerning the disclosure also depended on one's judgment of the relevance of cultural identity to the relationship, task, and interaction at hand. Some respondents emphasized that they did not consider their cultural background to be important at work. They were careful about not imposing the disclosure and informed others about their Russianness only when it was deemed "suitable," for instance, when one expected more interactions with a certain person or when one had valuable insights to share in an ongoing conversation concerning Russia.

The persons interviewed for this study were highly educated middle-class professionals who inhabited very special social spheres. There were inequalities also within this group. Access to sociocultural resources made it easier for some to enact their preferred identities (Collier 1998). For instance, those who spoke Finnish without a discernible 
Russian accent enjoyed more agency in disclosing or closeting their background. Also the type of work one performed and therefore the people one met at work resulted in different responses to having one's background "found out." Those employed in business and educational contexts, for instance, emphasized that the persons they met at work tended to be open-minded, tolerant, and multicultural, and "did not make a fuss" about someone's diverse background. As one person said, the cosmopolitan business culture embraced in her work community diminished the importance of her Russianness. When learning about her being Russian, people would usually make brief positive comments and move on to other more relevant issues:

\begin{abstract}
When I meet people they definitely hear my terrible accent in Finnish, so they usually ask where I'm from. I tell them that I'm Russian and, I don't know, maybe the business people I meet, for example I meet a lot of people at trade fares, maybe the business culture makes them polite or maybe they've already changed the way they think. They never ask questions in a way: "When will you go back home?" It's always more about: "How long have you been living in Finland?” or: "You speak Finnish so well.” That's what I usually hear. And then we switch to other topics.
\end{abstract}

However, respondents performing customer service work and therefore meeting members of the general public could not rely on such assumptions and occasionally faced negative or threatening reactions. The problem was further compounded by power inequalities inherent in customer service work where priority is given to pleasing the customer. A particularly striking account was given by a woman performing help desk work. She described how some customers, already upset about a faulty product or service, became even more irritated upon discovering that she was not Finnish and possibly Russian. The woman described situations where she had faced offensive ascriptions including racist slander. She struggled with feelings of anxiety in her daily encounters with customers as she was not able to predict how the other may react upon learning about her Russianness.

\title{
Facing stigma
}

Russian identity also designated a stigmatized group membership. It emerged in workplace interactions in terms of hurtful ascriptions based on the negative representations of Russians, and Russian women, circulating in social and media spheres in Finland.

Anti-Russian prejudice was experienced by many as a real social problem that occasionally surfaced in their workplace interactions. Persons working on organizational frontlines, such as in customer service, who frequently interacted with strangers, appeared to be at a higher risk of facing expressions of prejudice. This said, challenging interactions and relationships with coworkers and supervisors were also described. The expressions of negative attitudes included ignoring, openly avoiding, or belittling the other, making supposedly funny comments about Russians, becoming irritated and rude, making racist remarks, or slandering the other.

Some of the accounts subtly represented the effects of the stigma attached to being a Russian woman in Finland. They described facing negative ascriptions that emphasized one's sexuality, such as insinuations that one's relationship with a male colleague had 
erotic undertones or that Russian women came to Finland primarily to find a husband. One respondent described the difficult situation she found herself in when the organization where she had just received a permanent employment contract went bankrupt. If she lost her job, her visa application would be denied. She gave an account of an interaction with her female Finnish boss to whom she turned for help:

I [told her]: "You know, I have no idea what to do because I got this contract and my visa is now in the process and if I get fired, I'll have to go back [to Russia].” And then my boss she tried to joke, I guess, so she said: "Why don't you get married like all Russians do?" So they do have this stereotype and she was surprised that I hadn't been thinking about this option! [ ] And I was really surprised that she said it out loud, and she was surprised at my reaction, that it insulted me in a way. I said: "No, I'll go back and then I'll be looking for a job in Russia again.” And she said she hadn't heard of this kind of, you know, that women would come to Finland "just for work" and that they're not looking for anything more.

The supposedly tongue-in-cheek advice to marry a Finn in order to avoid problems with the immigration authorities insulted the respondent deeply. Her supervisor insinuated that Russian women came to Finland to find a husband and enjoy all the benefits this would entail, drawing on stigmatizing representations of Russian women. The respondent rejected the hurtful ascription by stating that there were other scripts available for her and, subsequently, that being a single Russian woman in Finland did not imply being on a prowl for a Finnish marriage partner. This account of coming to experience oneself as Russian also has a political dimension. Unlike the other participants, the respondent in question did not have a Finnish citizenship or a permanent resident status in Finland. Recent work in critical intercultural communication has discussed how stigmatized cultural identities are materially sanctioned and reproduced, as when immigrants with "second-class" nationalities face bureaucratic impediments designed to limit their freedom of movement and getting into employment (e.g., Drzewiecka and Steyn 2012). The respondent's experience of Russianness was also that of limited rights of movement and general bureaucratic constraints that infiltrated her working life and workplace interactions in very concrete ways. As the processing of her visa application was tied to her job contract, her position as an employee was quite powerless. When examined in this light, her rejection of the subjugating identity ascribed to her by her supervisor appears as a risky and ideologically loaded act.

Encountering stigma in interactions stirred feelings of confusion, apprehension, anger, and humiliation. These were managed in a number of ways, such as openly engaging with the abuser and rejecting or correcting hurtful ascriptions, ignoring offensive comments, or avoiding the abuser. Threatening encounters were also trivialized by presenting them as exceptional, influenced by contextual factors such as the other's personality or bad mood, and not limited to Russians in Finland. Comparisons between own fairly "safe" position and blatant discrimination faced by members of visibly different ethnic groups in Finland were also made.

Although the boundaries of the workplace were not impermeable to prejudice and one sometimes had to interact with persons who espoused negative views about Russians, it seemed that the workplace as a network of established interpersonal relationships and a system of shared norms protected one from more extreme manifestations of prejudice possibly existing in the mainstream society. It is noteworthy that the 
respondents unanimously talked about generally feeling authentic and comfortable in their working communities. The analysis revealed that the respondents' organizations treated diverse identities in two ways, neither of which was associated with ignoring or putting excessive emphasis on the issue of prejudice. One approach was to highlight shared professional and organizational identities, and it was perceived as personally and professionally validating. The respondents did not wish to receive special treatment at work on account of their "problematic" cultural background and wanted to be approached as individuals and experts in their own right. Alternatively, the respondents described their workplaces as openly and intentionally multicultural in terms of attitudes and policies.

The experience of having faced anti-Russian prejudice was not shared by all the respondents. Some views reflected that the respondents recognized their privileged position as highly educated professionals. One's workplace was presented as an exceptional safe community embedded in the more unpredictable society. An alternative opinion also emerged that de-emphasized issues of systemic oppression and handed responsibility for constructing the problem of discrimination to the media and immigrants themselves. Oversensitive to the issue of discrimination, immigrants expected to be discriminated against and interpreted their interactions accordingly. These ostensibly sensational and newsworthy experiences were exploited by the media, which exaggerated the problem and intensified immigrants' negative expectations even further. A related perception was that immigrants may draw on the concept of discrimination to mask or reject their individual responsibility for failures and unwillingness to develop as a human being.

\section{Facilitating intercultural learning}

Russian identity also emerged as interesting, personally enriching, and not work-related knowledge of the meanings and symbols of a different sociocultural system. It was invoked in workplace interactions where the respondents acted as facilitators for their colleagues' and customers' intercultural learning.

Some interactions took the form of boutique multiculturalism (Fish 1997) and entailed engaging with somewhat superficial constructions of Russianness in terms of external cultural markers such as cuisine, arts, customs, or traditions. These were considered as intriguing and enjoyable. The respondents described participating in informal conversations about Russian culture and society that they initiated themselves or that were prompted by their colleagues or customers. Enactments of Russian identity also included performances of cultural customs as when Russian foods were brought to work for one's colleagues to taste or people prepared Russian dishes or celebrated Russian festivals together. One participant described how her explanation that Women's Day was a bank holiday in Russia prompted her all-male coworkers to organize a small Women's Day celebration for her:

We have this Women's Day and we couldn't work with Russia on that day, we couldn't send emails, and I said: "Well, yeah, it's a big deal, we have a day off [in Russia]." I started telling a little bit—so they brought me sweets on that day. It was really nice, you know, we had a little coffee break all together. 
These activities were also extended outside work when colleagues were invited home to celebrate one's name day "the Russian way" or coworkers left for a mini-break to St. Petersburg together. It appeared that being a cultural entertainer who had funny anecdotes to share and could act as a guide during a trip to Russia was, to many, an integral part of how they were perceived by others at work.

Facilitating others' intercultural learning was also conducted through enacting cultural differences: "being Russian" and "communicating like a Russian." To some respondents it was obvious that their communication behavior was shaped by their cultural background. They felt "other" and believed that their colleagues saw them as such: more emotional, spontaneous, creative, collectivistic, and hierarchical. Through informal interaction one exposed one's colleagues to an experience of cultural difference that could impact upon their learning. Some believed that their colleagues had learnt about and adapted to their "Russian communication style" and had developed certain expectations of them related to their background.

Despite the intended positive character of these constructions, there were indications of tensions between avowed and ascribed identities. Some saw their cultural heritage as a vital part of who they were and wished that their colleagues would exhibit more active interest in it. They acknowledged, however, the legitimacy of the salience of professional identities in workplace interactions that designated cultural identities as more private and engaged in outside work. Conversely, those who did not consider Russianness as central to their self-concept did not feel the need to introduce Russian culture in conversations. Colleagues' and customers' expectations that one observed Russian traditions, followed the Russian media, or often visited Russia-and the resulting questions about Russian culture and society-stirred feelings of annoyance. They were perceived as identity ascriptions that one did not acknowledge or agree with, an imposition that collided with or diminished one's other identities as an individual and as a professional.

The enactments of Russian identity also took a more serious social and political form. No matter how central being Russian was to one's self-concept, many nevertheless saw themselves as agents for social change responsible for helping others develop more complex ideas about Russia. This was accomplished through workplace conversations about the social and political situation in Russia or the difficult history between Finland and Russia. One of the respondents told about how she and her colleagues engaged in joint reflection about how issues related to Russia and Finland were represented in the other country's media. These interactions point to how the workplace may become an arena for joint critical political activity.

It is notable that these interactions were understood to be not work-related but something extra occurring during coffee breaks when time permitted. Intercultural learning took the form of activities that were perceived as personally enriching but disconnected from organizational functioning. None of the respondents described a situation where she would contribute valuable culture-shaped perspectives and worldviews in work-related discussions that would encourage joint organizational learning and change, resounding Ely and Thomas' (2001) integration-and-learning perspective on diversity.

Furthermore, some voices reflected disinterest about such intercultural learning. Relational development emerged as diminishing or even eradicating the need to distribute knowledge about Russian culture or dismantle negative stereotypes about Russians. Many were content with having come to be perceived as individuals judged on the merits of their 
personality and professional expertise and not as representatives of Russia. Some had discussed their "cultural otherness" with their colleagues, and it emerged that their colleagues did not perceive them as "Russians," "foreigners," or "outsiders." It was further posited that one's cosmopolitan and knowledgeable colleagues did not require attitude work.

Also, some views suggested a rejection of the very concept of the supposed cultural distinctiveness of national and ethnic groups, and the possibility of distilling manifestations associated with one's cultural background. The taken-for-granted meanings accorded to "Russian culture" were critically reflected upon. Some did not perceive, and refused to define their specific enactments as expressions of cultural identity. It was, for example, pointed out that wearing feminine clothes or bringing souvenirs for one's colleagues do not necessarily symbolize Russian cultural identity but could be manifestations of one's personality or identification with a specific organizational culture. Popularly held national stereotypes were also jointly exposed in the work community. Some respondents, for instance, talked about their colleagues joking about how they were "more Finnish than Finns themselves," where it was the very representations of "Finns" and "Russians" that were being poked fun at.

\section{Discussion}

The goal of this article was to problematize the view of cultural identities as static, monolithic, and universally shared in the context of social interaction at work. An integrated interpretive and critical interpersonal perspective was adopted to analyze the respondents' experiences of coming to understand oneself as Russian in everyday workplace interactions. The findings identified four themes as possible sites for Russian identity formation: expressing professionalism, managing initial encounters, facing stigma, and facilitating intercultural learning.

In response to the first research question, the findings illustrate that cultural identity mattered to the respondents in unique ways. Each and every participant experienced her own Russian identity through interactions among her self-view, enactments, and relationships in a specific work community. While some respondents accorded greater salience, scope, and intensity to their cultural identity and saw their working life as an important context for being Russian or proving that one is not like "other Russians", others treated the working community as a site for other identities to be performed. Cultural identities are dynamic and constructed between and among people. Experiences of cultural identity as meaningful in interactions were interspersed with those communication situations where cultural identity did not emerge as prominent and the interaction was not framed as intercultural. By the same token, cultural identities were occasionally made visible and significant to the respondents by the words and actions of others. In response to the second research question, the themes expressing professionalism, managing initial encounters, facing stigma, and facilitating intercultural learning encompass the range of potential Russian identities residing in the respondents' workplaces that could become relevant with a different intensity in different settings. Therefore, negotiating one's cultural identity involved not only negotiating its salience as such in the interaction but also settling on the relevant meaning of Russianness. While the respondents had already agreed upon their preferred identities in their established workplace relationships, these had to be negotiated anew in initial interactions with newly met 
colleagues, customers, and business partners. This appeared to be especially challenging for persons working on organizational frontlines. At the same time, the context of expert knowledge work, with specific duties, responsibilities, types of tasks, interactions, relationships, and work community enabled and constrained cultural identity processes in significant ways. As work-related experiences, qualities, and skills were prioritized, individuals were given the possibility of being released from their cultural memberships. This provided them with an argument to counter possible negative cultural ascriptions. The context further empowered the respondents to avow positive Russian identity as a cultural expert, an entertainer, or an agent for social change when the moment was right. In response to the third research question, the themes within the data signify that there are a number of shared pivotal communication locations that serve as critical signposts for individuals coming to experience their cultural identity in workplace interactions. These locations help us understand contexts for the specific formations of cultural identity as residing in distinct topics, situations, relationships, and interactions. The themes of expressing professionalism, managing initial encounters, facing stigma, and facilitating intercultural learning embody the shared experience of how persons may orient themselves to cultural identities in workplace settings.

The different meanings accorded to Russian identity and the processes of their formation have implications for both organizational functioning and employee well-being. When examined in the light of previous research, the four themes carry traces of ideas developed in the organizational efficiency and discrimination strands. However, it appears that an interpersonal communication perspective taken in the study, together with the focus on identity processes per se, has revealed novel interpretations and experiences concerning the role of cultural identities in the organizational context.

The strand of organizational efficiency research that takes the information and decision-making perspective has been preoccupied with examining the organizational benefits of utilizing the diverse knowledge and perspectives of employees as promised by the discourse of diversity management. The findings of this study indicate that people differentiated between cultural identity as facilitating learning and as related to expressions of professionalism. Intercultural learning was perceived as personally enriching but disconnected from organizational functioning. Constructions of Russianness related to professionalism, in turn, pertained to individual enactments of work ethics or practical knowledge and skills applied solely in interactions with Russian customers or business partners. None of the respondents described a situation where her cultureshaped knowledge and worldviews would be applied with a view to enhancing general organizational-level knowledge construction or innovation. Perhaps the respondents' organizations were unaware of such learning possibilities or these issues were simply too difficult to grasp and relate in an interview. However, this finding does prompt a number of questions that deserve further investigation. Could the organizational value of culturally diverse perspectives and worldviews be overrated? How to distill experiences, knowledge, and skills associated with individuals' cultural identity from those related to their other identities? What is the process and content of intercultural learning among employees of culturally diverse organizations?

The argument of cultural synergy where different culture-shaped values and attitudes are forged to improve organizational functioning is further undermined by the apparent lack of agreement in the data about the purported shared contents of Russianness. Russianness was given distinct meanings (as represented in the four themes), but 
there is also evidence of a critical examination of meanings and expressions popularly associated with Russian identity and disjoining one's ostensibly cultural enactments from the cultural. These findings support the argument that issues of cultural identity and cultural diversity should better be approached as emergent and socially constructed rather than through applications of sets of a priori facts about psychological and behavioral characteristics of specific cultural groups (Lauring 2011). The interviews could further be approached as naturally occurring data and examined with a discourse analytical approach. Shifting attention onto how the respondents "do" cultural identities in their talk with the researcher could help interrogate meanings attributed to cultural identity that are otherwise assumed to be "normal" and "natural," therefore fulfilling the claim that cultural identities are constructed rather than expressed in communication (Mendoza et al. 2002).

With relation to the traditional social identity and categorization perspective, some of the accounts confirmed the assumption that workplace interactions could be experienced in terms of intergroup encounters. These accounts documented the highly emotional character of one's enactments at work as one struggled to disprove negative stereotypes about one's group or demonstrate that one was different from the other members of the group. However, this theoretical framework holds little explanatory power in the case of experiences of intraethnic competition that are also evident in the data. The findings of this study confirm the view that the prototypical intergroup situation where employees who are members of the disadvantaged minority group experience prejudice at the hands of the advantaged group is not the only possible scenario in culturally diverse organizational contexts (Taylor et al. 2008). Also in relationships with culturally close colleagues, cultural identities may surface as problematic, stirring feelings of threat and leading to biased reactions that impair both organizational functioning and employee well-being.

The findings tie in with the discrimination perspective in a number of ways. Russian identity construction is a problematic event as negative stereotypical and racist images of Russians and Russian women may enter the conversation in terms of subjugating ascriptions. The consequences of the social construction of cultural identities were of special significance for persons working on organizational frontlines and meeting strangers on a daily basis. These respondents' experiences of coming to be Russian were often at the mercy of others as they were required to explain or even negotiate the meaning of their background. Cultural identities are fluid and, in this sense, also dangerously fragile; those who do not experience themselves as different may unexpectedly become "othered" as the situational, social, political, and economic contexts change (Waldram 2009).

However, it should be considered that formations of Russian identity entailed all four themes (any of the four distinct meanings was possible) and that Russianness emerged with different degrees of salience, scope, and intensity. While some of the interviewees had faced stigma related to their ethnicity and gender, they did not wish to be defined as victims of prejudice and emphasized that those were only some among the many other ways that Russianness was formed in their workplace interactions. While nonmainstream employees' experiences of stigmatization should not be underestimated, we should also acknowledge other organizational experiences that people have. Obviously, the participants were middle-class independent "white" experts, which allowed them to put their professionalism and individuality front stage. This does not mean that their experiences should be underrated. It seems unfair that the social discussion 
of Russians (and other immigrant groups) in Finland pivots around the theme of prejudice and discrimination. Needless to say, these have been the dominant perspectives in Finnish research on Russian immigrants (e.g., Honkatukia 2005, Jasinskaja-Lahti et al. 2002, Kyntäjä 2005, Liebkind et al. 2004, Pohjanpää et al. 2003).

Also with relation to the paradigm of antidiscrimination, the findings give evidence to novel empowering interpretations of the discourse of diversity management. While this ideology has been much criticized for dissolving the basis for arguments about group-based systemic discrimination, it enabled the respondents to claim positive constructions of the identity that had been historically marked by stigma. By using arguments of possessing valuable cultural resources, the respondents improved their status as professionals and employees. This application of the discourse of diversity management is firmly situated within the recent changes in economic and social climate in Finland that have not yet been documented by research. Jaakkola's (2009) latest data on Finns' attitudes toward immigrants are from 2007; the inflow of Russian capital in recent years and the impact this has had on views about interacting with Russians is evident in the data. Certain constructions of Russianness in working life contexts are ascribed high value and prestige.

The findings further reveal tensions between cultural and other identifications. While some saw their workplace as an important site to enact Russianness, others treated the working community as a space where they could perform other identities. This finding challenges the dominant assumption that employees with different cultural backgrounds always experience themselves as culturally different and want to be treated respectively. There has been a tendency in research literature to express disapproval of organizational approaches that do not explicitly attend to minority employees' cultural backgrounds (e.g., Trux 2005). What if these employees are satisfied with their self-expressions, relationships, interactions, and possibilities for development? This argument could further be related to criticism of the field of intercultural communication as focusing on cultural differences, misunderstandings, and conflict (e.g., Ryoo 2005). Cultural workplace diversity scholarship and practice could benefit from acknowledging that interpersonal interactions among employees with diverse backgrounds are first and foremost interpersonal interactions. There may be working life situations where cultural identity is not a valid frame for individuals to define themselves and make sense of the social world.

\section{Acknowledgments}

The present article is part of the author's doctoral dissertation under preparation supervised by Professor Maarit Valo at the Department of Communication, University of Jyväskylä. The study received funding from the Finnish Work Environment Fund (project no. 112326).

\section{References}

Barinaga, E. (2007) ““Cultural Diversity” at Work: "National Culture” as a Discourse Organizing an International Project Group', Human Relations, 60(2): 315-340.

Burgess, R. G. (1984) In the Field: An Introduction to Field Research. London: Allen \& Unwin. 
Collier, M. J. (1998) Researching Cultural Identity. Reconciling Interpretive and Postcolonial Perspectives. In D. V. Tanno and A. Gonzalez (Eds.), Communication and Identity across Cultures (pp. 122-147). Thousand Oaks, CA: Sage.

Collier, M. J. (2005) Theorizing Cultural Identifications: Critical Updates and Continuing Evolution. In W. B. Gudykunst (Ed.), Theorizing about Intercultural Communication (pp. 235-256). Thousand Oaks, CA: Sage.

Collier, M. J. and Thomas, M. (1988) Identity in Intercultural Communication: An Interpretive Perspective. In Y. Kim and W. Gudykunst (Eds.), Theories of Intercultural Communication: International and Intercultural Communication Annual (vol. 12, pp. 99-120). Newbury Park, CA: Sage.

Drzewiecka, J. and Steyn, M. (2012) 'Racial Immigrant Incorporation: Material-Symbolic Articulation of Identities', Journal of International and Intercultural Communication, 5(1): 1-19.

Ely, R. J. and Thomas, D. A. (2001) 'Cultural Diversity at Work: The Effects of Diversity Perspectives on Work Group Processes and Outcomes', Administrative Science Quarterly, 46: 229-273.

Ferguson, M. and Porter, S. C. (2013) An Examination of Categorization Processes in Organizations: The Root of Intergroup Bias and a Route to Prejudice Reduction. In Q. Roberson (Ed.), The Oxford Handbook of Diversity and Work (pp. 98-114). Oxford: Oxford University Press.

Fish, S. (1997) 'Boutique Multiculturalism, or Why Liberals are Incapable of Thinking about Hate Speech', Critical Inquiry, 23(2): 378-395.

Forsander, A. (2001) 'Kenelle ovet aukeavat? Maahanmuuttajat ja työllistymisen ehdot' [Who is the Door Open for? Immigrants and the Conditions for Getting Employment], Työpoliittinen aikakauskirja, 2: 28-38.

Golden, D. R., Niles, T. A., and Hecht, M. L. (2002) Jewish American Identity. In J. N. Martin, T. K. Nakayama, and L. Flores (Eds.), Readings in Intercultural Communication (pp. 44-52), Boston: McGraw-Hill Higher Education.

Hecht, M. L. and Faulkner, S. L. (2000) 'Sometimes Jewish, Sometimes Not: The Closeting of Jewish American Identity', Communication Studies, 51(4): 372-387.

Hecht, M. L., Collier, M. J., and Ribeau, S. A. (1993) African American Communication: Ethnic Identity and Cultural Interpretation. Thousand Oaks, CA: Sage.

Holvino, E. and Kamp, A. (2009) 'Diversity Management: Are We Moving in the Right Direction? Reflections from Both Sides of the North Atlantic', Scandinavian Journal of Management, 25: 395-403.

Honkatukia, P. (2005) Väkivalta maahanmuuttajien kokemana ja kertomana [Immigrants' Experiences and Stories of Violence]. In S. Paananen (Ed.), Maahanmuuttajien elämää Suomessa [The Life of Immigrants in Finland] (pp. 119-136). Helsinki: Statistics Finland.

Hopson, M. C. and Orbe, M. P. (2007) 'Playing the Game: Recalling Dialectical Tensions for Black Men in Oppressive Organizational Structures', The Howard Journal of Communications, 18: 69-86.

Jaakkola, M. (2005) The Attitudes of Finns towards Immigrants in 1987-2003. Labour Policy Studies, 286. Helsinki: Ministry of Labor.

Jaakkola, M. (2009) Maahanmuuttajat suomalaisten näkökulmasta: Asennemuutokset 1987-2007 [The Attitudes of Finns towards Immigrants: Attitude Changes in 1987-2007]. Tutkimuksia 2009 (1), City of Helsinki Urban Facts. Helsinki: Edita Prima.

Jasinskaja-Lahti, I., Liebkind, K., and Vesala, T. (2002) Rasismi ja syriintä Suomessa: Maahanmuutajien kokemuksia [Racism and Discrimination in Finland: The Experiences of Immigrants]. Helsinki: Gaudeamus. 
Joronen, T. (2005) Työ on kahden kauppa: Maahanmuuttajien työmarkkina-aseman ongelmia [A Job is a Contract between Two: The Challenges of Immigrants' Position on the Labour Market]. In S. Paananen (Ed.), Maahanmuuttajien elämää Suomessa [The Life of Immigrants in Finland] (pp. 59-82). Helsinki: Statistics Finland.

Jung, E. and Hecht, M. L. (2004) 'Elaborating the Communication Theory of Identity: Identity Gaps and Communication Outcomes', Communication Quarterly, 52(3): 265-283.

Kasvio, A., Virtanen, S., and Kandolin, I. (2010) Työelämän muutos ja tulevaisuus [The Changes and Future of Working Life]. In T. Kauppinen et al. (Eds.), Työ ja terveys Suomessa 2009 [Work and Health in Finland] (pp. 9-44). Helsinki: Työterveyslaitos.

Kyntäjä, E. (2005) Venäläisten ja virolaisten leimautumiskokemuksia [The Experiences of Stigmatization of Russians and Estonians]. In S. Paananen (Ed.), Maahanmuuttajien elämää Suomessa [The Life of Immigrants in Finland] (pp. 137-156). Helsinki: Statistics Finland.

Lahti, M. and Valo, M. (2012). 'Cultural Diversity in Interpersonal Communication at Work: A Literature Review,' Manuscript submitted for publication.

Lauring, J. (2009) 'Managing Cultural Diversity and the Process of Knowledge Sharing: A Case from Denmark', Scandinavian Journal of Management, 25: 385-394.

Lauring, J. (2011) 'Intercultural Organizational Communication: The Social Organizing of Interaction in International Encounters', Journal of Business Communication, 48(3): 231-255.

Liebkind, K., Mannila, S., Jasinskaja-Lahti, I., Jaakkola, M., Kyntäjä, E., and Reuter, E. (2004) Venäläinen, virolainen, suomalainen: Kolmen maahanmuuttajaryhmän kotoutuminen Suomeen [A Russian, an Estonian, a Finn: The Integration of Three Immigrant Groups in Finland]. Helsinki: Gaudeamus.

Mannix, E. and Neale, M. (2005) 'What Differences Make a Difference? The Promise and Reality of Diverse Teams in Organizations', Psychological Science in the Public Interest, 6(2): 31-55.

Mason, J. (2002) Qualitative Interviewing: Asking, Listening and Interpreting. In T. May (Ed.), Qualitative Research in Action (pp. 225-241). London: Sage.

Mayan, M. J. (2009) Essentials of Qualitative Inquiry. Walnut Creek, CA: Left Coast Press.

Mendoza, S. L., Halualani, R. T., and Drzewiecka, J. A. (2002) 'Moving the Discourse on Identities in Intercultural Communication: Structure, Culture, and Resignifications', Communication Quarterly, 50(3\&4): 312-327.

Official Statistics of Finland (2013) Population Structure [e-publication]. ISSN=1797-5395. Helsinki: Statistics Finland [referred: 6.5.2013]. Access method: http://tilastokeskus.fi/til/ vaerak/laa_en.html.

Peltokorpi, V. (2007) 'Intercultural Communication Patterns and Tactics: Nordic Expatriates in Japan', International Business Review, 16: 68-82.

Piller, I. (2011) Intercultural Communication at Work. In I. Piller (Ed.), Intercultural Communication: A Critical Introduction (pp.76-95). Edinburgh: Edinburgh University Press.

Pohjanpää, K., Paananen, S., and Nieminen, M. (2003) Maahanmuuttajien elinolot [The Living Conditions of Immigrants]. Helsinki: Tilastokeskus.

Pyöriä, P. (2006) Understanding Work in the Age of Information. Finland in Focus. [A Doctoral Dissertation]. Tampere: Tampere University Press.

Richardson, B. K. and Taylor, J. (2009) 'Sexual Harassment at the Intersection of Race and Gender: A Theoretical Model of the Sexual Harassment Experiences of Women of Colour', Western Journal of Communication, 73(3): 248-272.

Ryoo, H.-K. (2005) 'Achieving Friendly Interactions: A Study of Service Encounters between Korean Shopkeepers and African-American Customers', Discourse \& Society, 16(1): 79-105. 
Saarinen, A. (2007) Venäläiset maahanmuuttajat "naisystävällisessä" Pohjolassa: Kansalaisuus ja stigmatisoitunut identiteetti [Russian Immigrants in the "Female-Friendly" North: Nationality and Stigmatized Identity]. In T. Martikainen and M. Tilikainen (Eds.), Maahanmuuttajanaiset: Kotoutuminen, perhe ja työ [Immigrant Women: Integration, Family and Work] (pp. 125-145). Väestöliitto, Väestöntutkimuslaitos, Väestöntutkimuslaitoksen julkaisusarja D 46/2007. Helsinki: Vammalan Kirjapaino.

Sandelowski, M. (2000) 'Whatever Happened to Qualitative Description?', Research in Nursing \& Health, 23: 334-340.

Spreckles, J. and Kotthoff, H. (2009) Communicating Identity in Intercultural Communication. In H. Kotthoff and H. Spencer-Oatey (Eds.), Handbook of Intercultural Communication (pp. 415-439). Berlin: Walter de Gruyter.

Sutela, H. (2005) Maahanmuttajat Palkkatyössä [Immigrants in Employment]. In S. Paananen (Ed.), Maahanmuuttajien Elämää Suomessa [The Life of Immigrants in Finland] (pp. 83-109). Helsinki: Statistics Finland.

Stevens, F. G., Plaut, V.C., and Sanchez-Burks, J. (2008) 'Unlocking the Benefits of Diversity: All-Inclusive Multiculturalism and Positive Organizational Change', Journal of Applied Behavioral Science, 44: 116-133.

Säävälä, M. (2010) 'Forced Migrants, Active Mothers or Desired Wives: Migratory Motivation and Self-Representation in Kosovo Albanian and Russian Women's Biographies', Journal of Ethnic and Migration Studies, 36(7):1139-1155.

Tanaka, H. (2006) 'Emerging English-Speaking Business Discourses in Japan', Journal of Asian Pacific Communication, 16(1): 25-50.

Taylor, D. M., Caouette, J., Usborne, E., and King, M. (2008) How Disadvantaged Groups Members Position Themselves: When They Might Appear to Work against an Improvement in Status for Their Own Group. In F. M. Moghaddam, R. Harre and N. Lee (Eds.), Global Conflict Resolution through Positioning Analysis (pp. 149-168). New York: Springer Science.

Thorne, S. (2008) Interpretive Description. Walnut Creek, CA: Left Coast Press.

Thorne, S., Reimer Kirkham, S., and O'Flynn-Magee, K. (2004) 'The Analytic Challenge in Interpretive Description', International Journal of Qualitative Methods, 3(1): 1-11.

Trux, M.-L. (2005) “"Ei sitä meillä kukaan kato”-Kansainvälisyys ja monietnisyys helsinkiläisellä IT-työpaikalla ["Nobody Pays Attention to That Here"-Internationalism and Multiethnicism at a Helsinki-Based IT Company]', Työpoliittinen aikakauskirja, 2: 49-69.

van der Zee, K., Vos, M., and Luijters, K. (2009) 'Social Identity Patterns and Trust in Demographically Diverse Work Teams', Social Science Information, 48(2): 175-198.

van Knippenberg, D., Homan, A. C., and van Ginkel, W. P. (2013) Diversity Cognition and Climates. In Q. Roberson (Ed.), The Oxford Handbook of Diversity and Work (pp. 220-238). Oxford: Oxford University Press.

Waldram, J. B. (2009) 'Is there a Future for "Culture" in Acculturation Research? An Anthropologist's Perspective', International Journal of Intercultural Relations, 33: 173-176. 